\title{
A Case Study on the Competence of New Employees Engaged in Power System Communication
}

\author{
Li Li*, Li Zhi Wang, Wen Ming Wang, Yan Heng Zhao and Wen Hua Shi \\ Department of Information and Communication Training, State Grid Technology College, Er Huan Nan \\ Road, Jinan, China \\ 1098160901@qq.com \\ *corresponding author
}

Keywords: operation and maintenance of communication system, competence framework, job training, workplace demands

\begin{abstract}
This paper conducts a case study focus on the difference between the quality of university education and job position demands. The study conducts a survey in some new employees recruited in 2017 by State Grid Corporation of China (SGCC) to get their professional background and their entry level comprehensive quality. Some of the new employees engaged in communication operation and maintenance participated in the investigation. A summary of statistics and results of the survey is presented and is compared with the professional workplace demands. The result reveals that there is a gap between university education and industry demands. Conclusions are drawn about some suggestions for personnel training of SGCC to bridge the gap.
\end{abstract}

\section{Introduction}

According to the trend of global energy interconnection developing, information and communication technology (ICT) plays a more and more important role in electric power industry. Global energy interconnection refers to the development of a globally interconnected, ubiquitous robust smart grid, supported by backbone UHV grids, and dedicated primarily to the transmission of clean energy. Smart grid is a new type modern power grid integrating modern information communication, automatic control and decision. ICT plays a key role in electric industry controlling, dispatch management and so on. It is the basis for implementing the grid intelligent, interactive and big electric network running control. ${ }^{[1]}$

So the electric power enterprise needs a significant number of professionals in information and communication technology. Recent years the SGCC recruited many new employees graduated from university for operation and maintenance of information and communication system. The new employees need a introduction training before they begin their professional work.

State Grid Technology College(SGTC) is a job competence training center supported by the SGCC. The duty of SGTC is to provide training for the new employees before their position and provide training for the professionals to upgrade their knowledge and skills.

Most new employees are graduated with bachelor degree or master degree. They have been educated for many years and will work on operation and maintenance. In order to train the new employees better, it is needed to find out what competence the employees have and what competence the workplace needs. So the trainers of ICT department of SGTC conducted a study focus on the difference between graduates quality and job position demands.

The study was conducted in 4 stages as follows:

Stage 1: investigate the industry demands for the position.

Stage 2: investigate the new employees on their arrival competency profile.

Stage 3: analyze the data collected to find the difference between graduates' quality and workplace demands.

Stage 4: propose suggestions for the training reform. 


\section{Investigate and Data Analysis}

The outline of job competence profile for communication system operation is built. An investigate is conducted about the entry level competence of new employee.

\subsection{Build the Outline of Job Competence Profile for Communication System Operation}

“The position classification standards of SGCC (trial of implementation)" compiled by Human Resources Department of SGCC describes the job of position of information and communication operation and maintenance as "applying associated operate skills engaged in the operation and maintenance of the power grid information and communication system". Based on that, the researchers interviewed some technical experts and experienced workers from the industry to understand the specific on-site job competence of communications operations and then outline the core competence profile to define the communication maintenance practitioner's knowledge requirements, skills and expectations. The job competencies may be categorized as General competencies and Job-specific competencies which includes three parts: knowledge, skill and attitude.

Competency profile are described in table 1:

Table 1 The competency profile of practitioner.

\begin{tabular}{|c|c|c|}
\hline $\begin{array}{c}\text { Types of } \\
\text { competencies }\end{array}$ & Description & Examples \\
\hline $\begin{array}{c}\text { General } \\
\text { competencies }\end{array}$ & $\begin{array}{c}\text { Core or common to } \\
\text { all jobs within an } \\
\text { organization }\end{array}$ & $\begin{array}{c}\text { Written and oral communication, problem- solving, } \\
\text { teamwork, time management, responsibility, } \\
\text { math foundation and information technology foundation, } \\
\text { electrical safety }\end{array}$ \\
\hline $\begin{array}{c}\text { Job-specific } \\
\text { competencies }\end{array}$ & $\begin{array}{c}\text { Concrete knowledge } \\
\text { and skill which are } \\
\text { required for success } \\
\text { in particular functions } \\
\text { or jobs }\end{array}$ & $\begin{array}{c}\text { Communication essential, optical transmission network, } \\
\text { network security, optical communication, ability to use } \\
\text { equipment such as OTDR, SDH, IMS, telephone switch } \\
\text { and so on }\end{array}$ \\
\hline
\end{tabular}

\subsection{A Survey on Entry Level Quality of Newly Recruited Employees}

Some interviews and questionnaires were conducted in the 2017 newly recruited employees to get their professional background and entry level competence, the new employees engaged in operation and maintenance of information and communication which attend the training class participated the survey.

\subsubsection{Interview With New Employees}

Based on job competence profile, an informal discussion was conducted with some trainees. The trainees are new employees from provincial companies and prefecture-level companies. The researchers randomly picked 15 individuals from 3 training classes, have an informal discussion with them.

Through discussion and communication, we know that new employees have learned general courses such as Mathematics, English, Programing, Computer Application and so on, and there are great differences in specific courses. The characteristics of students are: professional and basic theoretical knowledge, ability to apply foreign languages and computers, teamwork ability in work, and strong learning ability.

That is to say, these new employees have better general ability, but they know little about engineering practice, and the combination of theory and practice is not good enough.

\subsubsection{Questionnaire about the Specific Competence}

A questionnaire focused on the core job-specific competence is designed to gather information about the respondent's background and entry level . Most of the questions in the questionnaire are the type of "yes or no". The individuals answered the questionnaire anonymously by their self 
evaluation.

There is a question about the respondent's technical background, the choices for the question are: communication, computer, electric power relative, other.

A total of 152 questionnaires were sent to new employees before the training class, and 136 questionnaires were returned.

\subsubsection{The Results and Data Analysis}

According to the data collected from the participants, the professional background data of the new communication professionals are shown in table 2 :

Table 2 New employees’ professional background.

\begin{tabular}{|c|c|}
\hline Major & Proportion \\
\hline Electronics and telecommunication & $47 \%$ \\
\hline Computer science & $34 \%$ \\
\hline Electric power system & $10 \%$ \\
\hline Other & $8 \%$ \\
\hline
\end{tabular}

A large majority of the new employees graduate from electronic communications or computer science.

The data of the new employee's specific competencies include theoretical knowledge and practical skill are sorted in table 3.

Table 3 New employees’ specific competencies.

\begin{tabular}{|l|c|}
\hline \multicolumn{1}{|c|}{ Competency } & Affirmative answer ratio \\
\hline Know the fundamentals of computer network & $89 \%$ \\
\hline $\begin{array}{l}\text { Familiar with the fundamentals of communication and electronics } \\
\text { technology }\end{array}$ & $52 \%$ \\
\hline $\begin{array}{l}\text { Have the experience of using fiber fusion splicer } \\
\text { Have the experience of using optical time-domain reflectometer }\end{array}$ & $37 \%$ \\
\hline Know digital switch technology & $25 \%$ \\
\hline Know the power communication services & $24 \%$ \\
\hline Know the theory of EPON & $23 \%$ \\
\hline Have the experience of using SDH equipment & $21 \%$ \\
\hline Know the task of power communication maintenance & $20 \%$ \\
\hline Know the soft switch & $20 \%$ \\
\hline Know the theory of OTN & $20 \%$ \\
\hline Know the theory of IMS & $8 \%$ \\
\hline $\begin{array}{l}\text { Know program control exchanges and have the experience of } \\
\text { using program control exchanges }\end{array}$ & $8 \%$ \\
\hline
\end{tabular}

The data showed that most new employees are familiar with the principle of computer network and communication. the weakest points are: the theory of OTN, the theory of IMS, the theory of program control exchanges and the ability to use program control exchanges.

Analysis according to different professional backgrounds shows that there are significant differences in the knowledge structure of the new employees. The new employees from IT major are familiar with communication principle and electronic technology foundation, they have basic theoretical knowledge of communication system composition, digital communication, optical fiber communication, data network communication. However, only a little is known about the theory and practice of OTN and IMS technologies. There is less understanding of specific services for telephone communications and program control exchanges.

New employees from non-communication professionals, are not familiar with communication principles and lack understanding of basic communication knowledge. Know nothing about OTN, IMS theory and practice, little application experience of optical transmission equipment and 
program-controlled switching equipment.

This survey investigates newly recruited employees engaged in communications operations and maintenance in 2017. Participants come from different regions of the national grid and graduate from different universities. The data has a certain degree of representation.

As a whole, the new employees have good academic foundation and general competencies, but lack hands-on skills. The research analyzed the causes of this phenomenon. By consulting relative literatures about university curriculum, the research found that the common characteristics of university education are: different university curriculum settings are different, in general, there are many academic courses that include the principles of general courses and professional foundations, professional courses which differ in their specific professional directions are offered in senior years, ${ }^{[2][3][4]}$ while students in their senior year are under the pressure of taking postgraduate exams and graduating. They are hard to concentrate on learning, do not know what they will do in the future ,and do not know the use with professional courses. Perhaps this cause that the learning effect is not good. However, the teaching materials and experimental conditions of the experimental course lag behind the development of industrial technology. Students lack practical skills and specific experience.

According to "the Study Report on Telecommunication Engineering Professional Development", the education objective of communication engineering major in higher education is to have the knowledge of communication technology, communication system and communication network. The graduates can be advanced engineering talents engaged in research, design, manufacture, operation and the development and application of communication technology and equipment in the national economy and national defense industry ${ }^{[5]}$. The graduate will be a comprehensive talent with thick foundation and wide caliber, which is not exactly the same with the demand of electric power enterprises. Some college graduates have high expectations on their own career. They hope to conduct research and design work in institutions, but they can't fully adapt to the actual needs of maintaining jobs in communications and maintenance of power companies. There is a gap between job requirements and entry level for new employees.

\subsection{Some Suggestions on Training Improvement}

By comparing the new employees' competencies with actual needs of maintaining jobs in communications and maintenance of power companies. the research finds that the new employees graduated from university have good academic foundations and general skills, but they are lack of hands-on skills in workplace. They need to take job training to improve their specific competence. Based on the study, the researchers give some suggestions to improve the training.

\subsubsection{Suggestions for Training Program}

Considering the different professional backgrounds of new employees, the theoretical basis and practical basis is different, it is very difficult to carry out the same training for them. Then the focus of our professional skills promotion is to train the specific equipment application according to the actual work they are engaged in, mainly to enhance the ability of the new employees to operate the equipment, to install the hardware and to configure the parameters.

The current introduction training program includes enterprise culture, enterprise policy, and electrical safety and other general competencies and some core job specific competencies. The content of core job specific competencies is set up into three modules: optical transmission, telephone exchange, data network and information system. These three modules correspond to the main tasks of communication maintenance jobs.

In order to establish the overall cognition of electric power communication business and enhance self confidence of new employees, we should introduce on-site visits.

The ability to use the actual equipment capability is the weakness of the new employees. Therefore, we should emphasize the training of hands-on skills in training classes and increase the time for practical classes. Increase the time to operate SDH equipment, OTN equipment, optical instruments and data network equipment, and especially increase the time of theory and practice of OTN, since almost all students, regardless of their majors, have little knowledge of OTN 
applications, while OTN technology is becoming more and more widely used in power communication. As the use of IMS is spreading, we should add IMS introduction courses mainly involves theoretical knowledge, such as IMS architecture and IMS protocols.

We should cooperate with industry experts to design better training project to simulate actual workplace.

In addition, different power companies, such as provincial and municipal companies, are also different in their work. We should also conduct research on different types of companies. Accordingly, the emphasis of training is adjusted according to the specific posts of new employees. That is to say, focus on the new employees of the county company or the new employees of the provincial company, the training emphasis should be different. It is suggested to set up curriculum group corresponding to ability level and post, so as to achieve classified training according to different needs of trainee.

For the professional development of employees, in addition to introduction training and on-thejob training, special training on new technology applications must be arranged.

Training program and training curriculum will be revised timely as technology develops.

For the career development of employees and the formation of a lifelong learning atmosphere, it is recommended to better define the professional skills framework for employees, describe each capability classification and capability, and combine the capability framework to develop massive learning resources and carry out competency testing and certification examinations, and authorized organizations hold certification exams. In accordance with the professional post competency framework and qualification requirements, employees select learning content according to their own basics, professional positions, and work needs. Through the use of learning materials provided by the e-learning platform of the State Grid Corporation of China, they can acquire the knowledge of the accreditation module through self-study, and take the test to obtain the corresponding qualification certificate, qualification certificate can be used as a condition for career development and salary transfer. These can motivate employees to learn continuously.

\subsubsection{Suggestion for Training Environment}

To learn by doing is easier than by listening to lecture. There should be a field to supply traineecentered hands-on project. The picture exhibition board should be used to display the topology map of the application of power communication and the schematic diagram of the equipment, such as the dispatching data network, the remote control data transmission, the relay protection data transmission and so on, and the construction of the sand table model so that the students can see the overall situation of the power communication application.

The training room should be extended to increase the SDH equipment, OTN equipment, telephone exchange equipment and terminal access equipment, which are in line with the actual application of power communication. On the basis of full investigation, new training projects should be developed to enable trainees to grasp the skills of power communication operation and maintenance through specific projects. And comprehensive training projects related to practical applications should be developed.

\subsubsection{Suggestions for the Trainer Development}

The mature audiences in corporate training will bring in their own experiences and expectations, the purpose of learning is clearer. Maybe the adults' learning interest is not exactly the same, they have their own judgement about the choice of learning content. So trainer must strengthen ones industry-specific skills and enhance ones professional knowledge. Full-time trainers should strengthen the industry-specific skills by practice of workflow, experience the specific work of electric power communication, develop training projects with the experience of workplace. While technicians with rich experience should be invited to the campus as part-time trainers and they must be trained first to learn about teaching method.

\subsubsection{Suggestions for the Training Approach}

The employees could be trained in various forms of hands-on learning, project-based learning, e- 
learning, computer aided learning etc. and diverse training methods could be used.

Some theoretical courses or demonstrations of practical training courses could be designed as online courses, making full use of the State Grid Corporation Internet University platform to provide learning conditions for employees. Employees are required to study through the online university platform and pass the online theory exam before coming to the campus training class.

The campus training should focus on strengthening practical hands-on training of equipment applications. The task driven teaching method could be applied to simulate the actual engineering application with specific requirements, so that trainees should achieve their own goals. A reference catalogue of related theoretical knowledge is given to enable trainees to learn by themselves.

To train the trainees' team consciousness, divide them into study group, randomly select group members to report the presentation and demonstrate operation, promote collaborative learning and greatly improve the trainees' learning enthusiasm.

\section{Conclusion}

The research results show that there is a gap between the professional foundation of the new employees and the job needs, especially in the practical ability, so the training task is very difficult. The paper give some suggestions for training improvement. The suggestions may be useful for other department.

The development direction of the ICT is towarding wide brand, digitalize, intelligence, personalize, and synchronize. while cloud computing and cloud storage, big data, Internet of Things, power line communication etc. are getting more and more application in electric power industry. We should do as much as we can to get acquainted with new techniques, trace the development, refine the training program and training course system ceaselessly.

More research and assessment on job competency is needed. We will integrate the training resources and training power of the enterprise to do better training work.

\section{Acknowledgements}

This research work was supported by colleague of the information and communication training department and by a number of part-time trainers. Thanks.

\section{References}

[1] Liu Zhen Ya, (2015) global energy internet, china electrical publishing company.

[2] Peng Hui, (2015) Study on the Practical reform of the course system of Communication Engineering,Electronic Test. 16, 157-158.

[3] Zhang Da Min, Li Hui, (2014) Research on the Optimization Strategy of Communication Engineering Curriculum System, Heilongjiang Education, 5, 36-38.

[4] Wang Xia, (2012) Training Scheme Reform of Communication Engineering Characteristic Specialty, Journal of Wuhan University(Natural Science), 58, 104-106.

[5] Electronic Information Science and Engineering Professional Teaching Guidance Subcommittee, (2009) The Study Report on Telecommunication Engneering Professional Development, [EB/OL].http://www.edu.cn/yjbg_7796/20090212/t20090212_358392.shtml. 